out that these difficulties would be greatly enhanced if any attempt were made to absorb German men of science, while they might resent being placed in a position of subordination to Indian workers. His attitude towards the employment of Europeans in research in India provides much food for thought, and suggests that the educational situation of the future will call for tactful handling unless Indian education is to suffer. In the course of his interview, however, Acharya Roy does point out a weakness in the position of the European teacher, who, as an exile, looks forward to his return home, and as a foreigner cannot enter intimately into the life of his students.

\section{Classification of Sinanthropus}

When Dr. Hrdlička was passing through the press the revised edition of "The Skeletal Remains of Early Man" (Smithsonian Miscell. Collect., Vol. 83, 1930) he received a description, accompanied by photographs, of the then recently discovered skull of Peking man. Although it was too late for reference in the text, in an addendum Prof. Hrdlička gave it as his opinion that the skull was neanderthaloid, resembling the Galilee skull, and that "had it been found in Europe or in Asia Minor it would hardly be taken by any expert student . . . as anything else than neanderthaloid". Dr. Hrdlicka has now made a careful examination of cranial and endocranial casts of the Peking skull recently received from London, examining them side by side with comparable material in the National Museum collections at Washington. According to a communication issued by the Smithsonian Institution of Washington, Dr. Hrdlička finds that his previous conclusions are fully substantiated. They are in complete agreement with the view recently put forward by Dr. E. Dubois before the Dutch Academy of Sciences, being in effect that Peking man is a somewhat variant member of the widespread Neanderthal race. Though the brain and skull are small, Dr. Hrdlička holds that the former is "thoroughly human", if low in type, while the latter is comparable in capacity with the skulls of prehistoric Peruvians in the Washington collections, of which some thirty in number are less than 1,050 e.c. in cubic capacity. In respect of both characters, Peking man is thus brought well within the range of the human.

\section{Guiding Aeroplanes when about to Land}

IN the radio range-beacon system now used on American airways, it is sometimes very difficult to determine the absolute direction of the aeroplane when it is near the radio beacon. The pilot can easily pass from one quadrant to another without knowing it. When once so lost, he may wander many miles from the beacon before he can find out which quadrant he is on. Tests show that the average pilot, when flying under the hood and purposely lost, requires about an hour to find his course. In the Journal of Research of the Bureau of Standards for September, Mr. F. W. Dunmore describes aural, visual and combined methods which enable the pilot to identify the quadrant with certainty. In the aural method, directive signals are sent out; a one dot signal in a westerly direction, two dots easterly, three dots north and four dots south. Depending on which set of these signals is the loudest, a pilot can determine his general direction from the beacon. During an interval between the sending of the beacon station identification letter, the one dot and two dot signals are sent out, and during the next interval the three dot and four dot signals are transmitted; which two of the four sets of signals are heard loudest enable the pilot to determine his course. In the visual system, use is made of an indicator the reeds of which are affected by the signals, and their relative amplitudes enable the course to be determined. An advantage of the system for course and quadrant identification is that it can be readily applied to existing beacon stations as it requires no alterations to the antenna structure. Photographs of the devices and full diagrams of the necessary circuit arrangements are given.

\section{Inductive Interference with Telephone Lines}

THE working of telephones is often seriously impaired by the noise due to induction from neighbouring power or railway lines. This problem has been closely studied by electrical engineers for the last thirty years. In a paper communicated to the Institution of Electrical Engineers on November 23, Mr. W. G. Radley and Dr. S. Whitehead show that rapid progress has been made in the solution of the problem during the last few years. The amount of the interference in any given case can now be deter. mined quite definitely by mathematics. It is due both to electromagnetic and electrostatic induction and also in some cases to radio effects. The loss in the 'articulation' of a telephone depends on the frequency of the disturbing voltage. For example, to produce the same loss in articulation by means of a note having a frequency of 150 as a note having a frequency of 1050 , at which the maximum disturbance occurs, the induced voltage would have to be increased 158 times ( 22 decibels). The Post Office has now made a 'noise' meter which gives at one reading the magnitude of the interference factor produced by all the induced harmonics. It is a great step in helping the electrical industry to know that interference with existing telephone systems by any projected power or railway scheme can now be predetermined in advance. If it is too great, it can be decreased by a suitable choice of generators, the use of power cables or telephone cables instead of overhead circuits, etc. When there is a short circuit on the power line, and there are large transitory earth currents, there is risk both of electric and acoustic shocks. These may be partly mitigated by protective devices.

\section{Thermodynamic Storage of Energy}

THE equalising of the normal daily load of an electricity works with its sudden 'peaks' and deep drop at night is one of the fundamental problems of electrical engineering economics. The suggestions recently made that many of the European power 
stations might be linked together so that the peak load might be distributed more evenly, shows how seriously engineers regard the problem. Where Nature makes it possible to collect large quantities of wates by the building of dams across valleys and utilising the supplementary energy of hydraulic power stations for yearly storage, the peak demands may be economically covered for months. If the capacity is not sufficient, it can be augmented by using storage pumps to utilise the surplus energy available at night time. In many cases the initial costs of these methods are prohibitive. In the Escher-Wyss News for June, published by the EscherWyss Engineering Works, Ltd., of Zurich, Dr. Marguerre describes his thermal process for storing surplus energy. The principle may be explained by comparing it to that of a hydraulic pumping storage plant. In this plant, water is pumped from a low to a high level by utilising surplus energy. This energy is then recovered when required by allowing the water to fall to the lower level. In the thermodynamic method, heat is pumped from a low to a high temperature by means of the heat pump (turbocompressor) and the energy recovered in a steam turbine by a similar ternperature drop. The efficiency under average conditions is about 50 per cent. The costs are worked out for practical cases. The method can be used advantageously in connexion with town heating services

\section{Water Heating by Electricity}

Is order that heating water by electricity may be an economic proposition, it is necessary that electricity be sufficiently cheap. If the price is less than a penny per unit, the method is worth considering. A recent estimate made by the British Electrical Development Association of 2 Savoy Hill, W.C.2, shows that there are already two million houses in Great Britain connected to the supply mains in areas where electricity is offered at the price of $\frac{3}{13} d$. per unit. The Association issues a pamphlet in which it shows that electricity provides an excellent hot water service and that the supply of hot water reduces very appreciably household drudgery. When hire or hire-purchase terms are available, there is little capital outlay. Prospective users are advised to call at electricity show-rooms and builders are encouraged to make provision for electric hot water systems in new houses. In France, the Societe pour le Developpement des Applications de l'Electricité has recently estimated that the number of storage water heating appliances in France exceeds 20,500. There are, however, only 81 with a capacity equal to, or exceeding, 1,000 litres.

\section{Home-Grown Timber in Great Britain}

The Inter-Departmental Committee in homegrown timber appointed by the Forestry Commissioners in December 1931 has issued an interim report (Forestry Commission. Interim Report of the Inter-Departmental Home-Grown Timber Committee, 1933. London: H.M. Stationery Office. 4d. net). The terms of reference were: "To investigate and submit proposals for improvement in the utilisation of home-grown timber". The report states that the appointment of the committee arose out of the urgent need of redressing to some extent the adverse balance of trade in Great Britain by the increased use of home-grown products. The Committee believes that with adequate organisation and a measure of protection, there should be a greatly increased use of home timber, employing some thousands of men and replacing a part of the imports from foreign countries.

THE report now available gives the area which is classified as woodland in Great Britain as nearly $3,000,000$ acres (the accepted area before the War), of which some 300,000 acres are under State management, including 230,000 acres of young plantations made by the Forestry Commission since 1920. Approximately 2,700,000 acres are private property. On most private estates, forestry is said to be now at a low ebb, from causes well known and often recapitulated. The marketing of timber forms one of the subjects commented upon by the Committee. The want of any co-ordinated system and the high costs of transport, partly-but only partly-an outcome of the absence of any definite system, have for long been subjects of discussion and complaint. The Committee recognises that if railway rates are to be lowered a guaranteed quantity of traffic is necessary, which in the past has not been forth. coming. The Report states that the immediate problem the Committee has to face is concerned mainly with the utilisation of timber of small size and low quality which will not stand heavy haulage and conversion costs. It is suggested that the smaller estates "should market their timber through a central organisation in touch with various trades using wood, and guarantee a regular supply".

\section{Radio Communication in Mines}

THe August number of the Transactions of the Mining and Geological Institute of India is to hand. Most of the papers in it are of interest mainly to those engaged in mining work in India, but the first paper, by P.I. Keith-Murray on radio communication applied to mines, is of more general interest. The author has devoted considerable attention to the subject of radio communication, and has investigated in some detail the various methods with regard to their applicability to mining purposes, and more especially to mine rescue work. He has come to the definite conclusion that, so far, no place has been found for it in this work, but he also states that in view of the rapid development of all branches it would be unwise to make any definite statement as regards the impossibility of ever employing it in the future. He shows that a great deal of important work has been and is being done, and that new methods are being evolved at a tolerably rapid rate, and appears to hope that within a measurable distance one or other of these methods may be employed for underground work, though he points out fairly enough the very serious obstacles that it application would present. 